\title{
SOB A PLUMA DA MULHER: IDEALIZAÇÕES E TRANSGRESSÕES EM INDIANA, DE GEORGE
}

\author{
SILVA, Nilson Adauto Guimarães da ${ }^{1}$ \\ OLIVEIRA, Daiane Basílio de ${ }^{2}$
}

RESUMO: Em 1830, George Sand, escritora francesa, publica seu primeiro romance, Indiana, no qual elabora uma trama sentimental cujo pilar é a crítica à sociedade patriarcal, mais precisamente à forma como a mulher era tratada no matrimônio. Obra e escritora destacam-se pelo fato de romper com os paradigmas de uma sociedade cujo espaço de escrita pertencia em demasia aos homens. Além de abordar temas que eram tabus para a época, como o adultério, Sand torna visível a condição da mulher no âmbito público e privado, denunciando as opressões e rompendo com paradigmas da ideologia dominante que a marginalizava. Indiana é uma das primeiras obras literárias a registrar a escrita de autoria feminina e o discurso em defesa da emancipação da mulher e da igualdade de gênero. Mediante a análise de Indiana, observaremos como se constrói o discurso literário que se presta a denunciar a situação da mulher na sociedade francesa de 1830 , bem como a defesa da emancipação feminina.

PALAVRAS-CHAVE: George Sand, Indiana, literatura de autoria feminina.

\section{SOUS LA PLUME DE LA FEMME : IDÉALISATIONS ET TRANSGRESSIONS EN INDIANA, DE GEORGE SAND}

\begin{abstract}
RÉSUMÉ : En 1830, George Sand, écrivain français, publie son premier roman, Indiana, récit sentimental dont le pilier est la critique de la société patriarcale, plus précisément la manière dont les femmes étaient traitées dans le mariage. L'œuvre et l'écrivain se distinguent par leur rupture avec les
\end{abstract}

\footnotetext{
${ }^{1}$ Professor de Língua e Literatura francesas na Universidade Federal de Viçosa - UFV.

${ }^{2}$ Doutoranda em Literatura Francesa pelo Programa de Pós-graduação em Letras Neolatinas da Universidade Federal do Rio de Janeiro - UFRJ.
} 
paradigmes d'une société dont l'espace d'écriture appartenait trop aux hommes. En plus d'aborder des questions qui étaient taboues à l'époque, comme l'adultère, il rend la condition des femmes visibles dans les sphères publiques et privées, en dénonçant l'oppression et en rompant avec les paradigmes de l'idéologie dominante qui les marginalisaient. Indiana est l'un des premiers œuvres littéraires à enregistrer l'écriture par des femmes et le discours en faveur l'émancipation des femmes et l'égalité des sexes. À travers l'analyse d'Indiana, on observera comment se construit le discours littéraire qui se prête à dénoncer la situation des femmes dans la société française de 1830, ainsi que la défense de l'émancipation féminine.

MOTS-CLÉS : Mots-clés: George Sand, Indiana, littérature des femmes.

\section{INTRODUÇÃO}

A obra literária é também um documento historiográfico por via da qual se assenta a contemplação das vozes dos excluídos da história, a exemplo das mulheres, avultando práticas sociais desacauteladas e reelaborando maneiras de conceber a história e a leitura do texto literário.

Mais do que um ofício ou atividade, a escrita tem em si as ferramentas necessárias para aqueles que buscam externar os sentidos do mundo, desnudar realidades, dar forma a pensamentos e encontrar um espaço de legitimação social. Para George Sand, escritora francesa do século XIX, e para tantas outras mulheres que ousaram ocupar e se estabelecer no campo literário de seu tempo, tais ensejos encontram barreiras que em sua maioria são pautadas nas limitações sociopolíticas do ser mulher.

Por mais de quatro décadas, a trajetória literária de George Sand (1804-1876), pseudônimo de Amandine Aurore Dupin, resultou na produção de um acervo literário que conta com significativo número de romances, novelas, contos, peças teatrais, autobiografias, críticas literárias e correspondências. A escritora manteve, ainda, relação com o mundo editorial, contratos com revistas literárias e jornais como a Revue des Deux Mondes e Calmann-Lévy, além de participar na fundação e administração de revistas e jornais que buscavam dar voz às 
demandas populares, como a Revue indépendante em 1841 em companhia de Leroux ${ }^{3}$ e Viardot ${ }^{4}$, o Éclaireur de L'Indre e La Cause du peuple.

Em seu extenso projeto de criação literária, é possível enveredar na observação de diversificadas estratégias enunciativas empregadas para alcançar e manter os capitais necessários para o seu estabelecimento no campo literário francês de seu tempo, o que não a poupou de sofrer diversas censuras e apagamentos. Em meio às restrições de direito civil, a grande dama de Nohant, a escritora que se vestia como homem, aquela que segundo Gustave Flaubert é aclamadamente o "grande homem do século", iniciou sua trajetória literária em 1832 ao publicar Indiana, romance que dedica contundente crítica à sociedade patriarcal, mais precisamente à forma como a mulher burguesa era tratada na estrutura matrimonial.

Tal romance introduz uma série de valores que legitimam a voz enunciativa em todo o projeto de criação literária de George Sand. Segundo a própria autora na autobiografia Histoire de ma vie (1885), parte substancial de seu projeto de criação literária descortina problemas enfrentados socialmente pelo povo e pelas mulheres, movimentando-se em torno de demandas que se ajustassem à conjuntura do Estado Francês. Assim, o presente artigo se dedica a abordar como a escritora, em sua primeira publicação, constrói um discurso literário em que denuncia a condição da mulher na sociedade francesa.

\section{A criação literária de George Sand}

O que é criação literária para a mulher naquele momento histórico, na França? Filha de aristocrata, engajada com a causa das mulheres e dos camponeses, George Sand exigia da literatura o cumprimento de uma função social ou política e condenava o que chamava de "arte egoísta", a arte pela arte, como indica Bourdieu (1996, p. 96). Visava obter do leitor, pela força da escrita, o olhar arguidor sobre o mundo social e político. Por isso, a subjetividade enunciativa inscrita em seus romances resultou em seu reconhecimento no campo literário, apesar dos impedimentos devido aos poucos direitos civis acessíveis às mulheres.

A exclusão da mulher se efetuava de tal forma na vida social que sua ausência e tentativas de silenciamento eram compreendidas no meio intelectual, político e cultural. $\mathrm{Na}$ literatura, o fracionamento foi exteriorizado dada a oposição do homem, a quem era outorgado a designação de criador e sujeito da representação. Ao feminino, foi proscrito o lugar de sujeito

\footnotetext{
${ }^{3}$ Pierre Leroux (1798-1871), filósofo e político francês.

${ }^{4}$ Louis Viardot (1800-1883), escritor, crítico literário e tradutor francês.
} 
criado e representado. No âmbito social, não era admirável que a mulher exercesse o labor da escrita literária, o fazer literário era competência masculina.

O acesso à escrita, domínio sagrado, é também uma zona de afrontamentos e de controvérsias [...]. A "mulher autora", esta "pretensa literata" detestada, atrai para si todos os sarcasmos. Uma mulher que escreve, e sobretudo, que publica, é uma mulher desnaturada que prefere abrigar-se sob um pseudônimo masculino. Seu sucesso provoca escândalo: ele é depreciado. Vejamos George Sand e seus "romances rústicos". Relegados à prateleira da Biblioteca Verde para adolescentes (La Petite Fadette, La mare au Diable), eles fizeram esquecer a obra multiforme de uma escritora imensa, que redescobrimos apenas nos dias de hoje. (PERROT, 1998, p. 271)

Sand inaugura, dessa forma, uma nova postura superando as posições já determinadas, "na dianteira dessas posições, na vanguarda, e, introduzindo a diferença, produzir o tempo" (BOURDIEU, 1996, p. 181). Sobre seu primeiro romance, ela declara:

Escrevi Indiana com o sentimento não fundamentado, mas profundo e legítimo, da injustiça e da barbárie das leis que ainda governam a existência da mulher no casamento, na família e na sociedade. (SAND, 1885, p. 19, tradução minha $)^{5}$

Segundo uma publicação da Revue de Paris datada de setembro de 1832, Indiana atraiu demasiada atenção da crítica graças à novidade temática, riqueza de detalhes e verossimilhança, posto que é realista quanto às teses sociais. Para seus contemporâneos, o romance revela senso e valores autobiográficos e a universalização da experiência feminina.

Em 15 de maio de 1832, o Journal des débats anunciou o lançamento de Indiana. Distanciando-se da moda de seu tempo, George Sand se ligava ao romance realista, ela colocava sob evidência a situação da mulher dentro da família de 1830. A romancista abordava de maneira crítica um problema que

\footnotetext{
${ }^{5}$ J'ai écrit Indiana avec le sentiment non raisonné, mais profond et légitime, de l'injustice et de la barbarie des lois qui régissent encore l'existence de la femme dans le mariage, dans la famille et dans la société (SAND, 1885, p. 9).
} 
não poderia deixar os leitores indiferentes: aquele do casamento e do adultério. (BORDAS, 2004, p. 172, tradução minha) ${ }^{6}$

A crítica da época, a exemplo de Sainte-Beuve, articulava a análise da obra literária tendo em vista as propriedades formais do texto, como a estruturação da narrativa, conteúdo e estilo, contudo não exclui as impressões em torno do social, segundo as quais o romance se apresenta tanto no plano poético quanto no político, coroado tanto pelo forte realismo.

No contexto de publicação do romance, já havia um público leitor formado por mulheres, ainda que não substancial como o masculino, visto que a educação feminina era um privilégio para as mulheres provenientes dos meios abastados. Infere-se, por conseguinte, que o romance de George Sand consegue chegar às estantes de muitas mulheres, mesmo com a censura por parte da Igreja e daqueles que consideram tanto o romance quanto a escritora enquanto amorais.

Os efeitos ideológicos do romance não são redutíveis a meras repetições das representações patriarcais, estão articulados a novas formas de pensamento e concepção do universo social feminino. Indiana é, por isso, concebida como uma obra que ousou explicitar a situação da mulher no ambiente público e privado.

Na Magazine Littéraire de maio de 2004, fora citado: "Mulher? A questão é inevitável" de Christine Planté, e de Michelle Perrot: "George Sand não traiu o feminismo". Para essas duas autoras, se a baronesa de Dudevant não foi exatamente uma das primeiras combatentes feministas, seus romances evidenciaram claramente os problemas, e pessoalmente, ela soube preservar seus direitos, obtendo uma separação amigável e depois judicial com seu marido Casimir Dudevant. Graça aos seus talentos de escritora, ela demonstra que uma mulher pode obter autonomia financeira, coisa rara para a época. (RENARD, 2004, p. 28, tradução minha) ${ }^{7}$

\footnotetext{
${ }^{6}$ Le 15 mai 1832 le Journal des débats annonça la mise en vente d'Indiana. S'éloignant de la mode du temps, George Sand s'attachait avec ce nouveau roman à la réalité, elle croquait sur le vif la situation de la femme dans la famille de 1830. La romancière abordait de façon critique un problème qui ne pouvait laisser les lecteurs indifférents : celui du mariage et de l'adultère (BORDAS, 2004, p. 172).
}

${ }^{7}$ Dans « Le Magazine Littéraire » de mai 2004 déjà cité : «Femme ? La question inévitable » de Christine Planté, et de Michelle Perrot "George Sand n'a pas trahi le féminisme » (17). Pour ces deux auteurs, si la baronne Dudevant ne fut pas à la pointe des premiers combats féministes, ses romans ont à l'évidence posé clairement les problèmes, et à titre personnel, elle a su préserver ses droits en obtenant une séparation d'abord amiable, puis 
Indiana foi considerada como um forte grito de cólera contra a sociedade e sobretudo contra o casamento por parte de seus contemporâneos. E, em toda sua trajetória literária, a escritora não cessou de retratar a realidade das classes minoritárias e das mulheres. Em Histoire de ma vie (1855), Sand esclarece suas convicções sobre sua identidade e sua posição diante da história e do poder: "Eu sou a filha de um patrício e de uma mulher do povo [...] Estarei ao lado do escravo e da mulher do povo, e não com os reis e seus partidários” (SAND, 1855, p. 11, tradução minha) ${ }^{8}$.

\section{O discurso emancipatório em Indiana}

O papel performático da linguagem e sua função mediadora das ações na esfera social demonstra a vivacidade da palavra nas instâncias do poder. A manifestação da identidade individual e coletiva está relacionada ao reconhecimento da diversidade a qual gera instabilidade na esfera literária para o conceito de cânone e viabiliza o debate sobre os valores da produção literária dos grupos minoritários. É neste ponto que Sand, com Indiana, emerge com uma enunciação cujos valores incorporam a necessidade do expressar-se enquanto mulher e sobre a mulher, produzindo um romance cujo protagonismo não se situa sob a projeção da luz moral do homem.

Neste sentido, o discurso literário não atua somente como enunciado, mas é de igual maneira uma instituição, vetor de um posicionamento que considera as condições históricas de produção de sentidos nas quais os sujeitos estão inscritos. Reportar às obras às suas condições de enunciação remete a essas categorias precedentemente mencionadas: o estatuto do escritor no campo literário, os papéis vinculados aos gêneros, o contato estabelecido com o destinatário através da obra, os suportes materiais e os meios de circulação dos enunciados. "A obra não se limita a representar um real exterior a ela, mas define igualmente um quadro de atividade que é parte integrante do universo de sentido que ela simultaneamente pressupõe e pretende impor" (MAINGUENEAU, 2006, p. 229).

judiciaire d'avec son mari Casimir Dudevant. Grâce à ses talents d'écrivain, elle démontre qu'une femme peut obtenir son autonomie financière, chose rare à l'époque (RENARD, 2004, p. 28).

8 "Je suis la fille d'un patricien et d'une bohémienne [...] Je serai avec l'esclave et avec la bohémienne, et non avec les rois et leurs suppôts" (SAND, 1855, p.11). 
Em Indiana, a idealização dos personagens tem muito em comum com a política. Indiana é um tipo, é a mulher carregada de paixões suprimidas pelas leis e pela moral, com sentimentos e desejos que almejam romper com os limites da civilização. Nela, percebemos a mulher que, envolta em um contexto que não lhe sugeria outra coisa senão a passividade, quebra com a mesma através do adultério, o que alude ao rompimento com o sistema de leis e à queda do alinhamento à moral. Ela não consegue uma fuga física imediata, mas impugna seu matrimônio pelo viés do discurso e do adultério.

Além da forte representatividade da história das mulheres, é possível a percepção das marcas dos acontecimentos históricos via diálogos entre os personagens, bem como do panorama político e social pertinente às mulheres e das cenas históricas representadas na obra. A conjuntura histórica e a criação artística, segundo Candido (2006), residem em contiguidade nas obras literárias.

Na cena enunciativa de Indiana, o dispositivo institucional, os conteúdos manifestos e a relação interlocutiva se entrelaçam e se sustentam mutuamente de forma a se legitimarem (MAINGUENEAU, 2006, p. 135). É graças a essa legitimidade que é possível ao interlocutor apreender o pano de fundo da narrativa, a retratação de uma determinada época e localidade, a França do século XIX. O profuso realismo com que o romance é narrado e sua elocução veiculam a esfera social, de maneira que esta não se conforma exclusivamente como um fundamento externo, como código que viabiliza o reconhecimento da expressão de determinada época ou de uma sociedade no conteúdo da obra; "nem como enquadramento, que permite situálo historicamente; mas como fator da própria construção artística" (CANDIDO, 1965, p. 7).

Contemplamos, no romance, cenas políticas da vida privada e cenas públicas nas quais os personagens se encontram em meio aos episódios históricos. A narrativa decorre entre a Restauração e a Revolução de julho de 1830, sendo que esta última, curta, porém violenta, pôs fim a primeira. Indiana é, por isso, controversa e revolucionária diante da situação política do século XIX, tanto em vista da história e reinvindicação das mulheres, quanto do ponto de vista histórico, dos valores morais, coloniais e abolicionistas com base nas imbricações entre as duas nações europeias.

Em relação a isso, o modelo de estado patriarcal na França do século XIX, outorgado pelo Código Napoleônico, previa e legitimava a supremacia do homem na sociedade. A mulher se encontrava, neste contexto, como exemplo de amansada, domesticada, submissa, tendo suas responsabilidades restritas ao âmbito doméstico. No contexto de produção da obra, o homem 
era senhor do espaço público, porém, como este espaço e seu gênero eram considerados superiores, o âmbito doméstico acabava subordinado também a ele, o que dava uma falsa autonomia às mulheres. A suposta "liberdade doméstica" só existia efetivamente quando se alinhava aos interesses do pai ou marido, como demonstra Hunt (1991):

Os revolucionários limitaram o papel das mulheres ao de mãe e irmã dependendo, para suas identidades, dos maridos e dos irmãos; Sade as converteu em prostitutas profissionais ou em mulheres cujo papel principal é sua disposição em se deixarem acorrentar pelos homens, tendo como única identidade a de objetos sexuais. Nessas duas representações do privado, as mulheres não possuem qualquer identidade própria - pelo menos é o que desejam os personagens masculinos, pois, na verdade, elas são apresentadas como destruidoras em potencial, como se fosse mais do que evidente que jamais aceitariam voluntariamente os papéis que lhes são designados (HUNT, 1991, p. 49).

Ao romper com os discursos tradicionais, Sand não somente reivindica sua liberdade de escrita, como também o desejo pela liberação do seu "eu" tão reprimido pelos mecanismos e sujeitos opressivos presentes nas esferas pública e privada. Enquanto intelectual, ela evidencia determinadas situações de opressão sobre a mulher em sua cena de enunciação com o escopo de "subverter o poder da autoridade" (Said, 2005). Sand articula aquilo que acredita por meio de suas obras literárias, traçando denúncias ao comportamento masculino e à condição da mulher na sociedade.

De acordo com Zolin (2009), as obras canônicas, em grande parte, representavam a mulher sob a ótica dos estereótipos culturais, a mulher sedutora e imoral, a megera, a indefesa e incapaz, a mulher como anjo, e outras diversas definições. "A representação da mulher como incapaz e impotente subjaz uma conotação positiva; a independência feminina vislumbrada na megera e na adúltera remete à rejeição e à antipatia" (ZOLIN, 2009, p. 226). Embora a obra edifique o estereótipo do homem mais velho e experiente em detrimento da mulher mais jovem, inocente e ignorante, a representação da mulher na obra de George Sand subverte os princípios da ideologia dominante, lançando a figura feminina em um contexto que desmascara as opressões e que lhe atribui superioridade. 
$\mathrm{Na}$ primeira fase da narrativa, contemplamos uma Indiana totalmente imersa em um contexto que lhe impunha passividade. No entanto, essa imagem transita no sentido emancipatório da personagem. Indiana é a personificação da mulher como ser social lançado ao silenciamento, é ela a porta voz de um discurso contestador, é por meio dela que se denuncia a condição das mulheres no lar e no meio público, é a tipificação da mulher do século XIX.

Diante da estética romântica, a idealização da protagonista expressas em suas características psicológicas e ações contraria as expectativas, tendo em vista a produção literária que se modulava à moral da época. A progressão dessa mulher, que a princípio se guarda submissa e emudecida, representa a percepção do feminino marcado pelo silenciamento, pela consciência social e pelas dores que lhe sobrevém ao tentar conservar o seu caráter e anseio por ser livre.

Indiana foi criada em meio aos escravos como senhora, contudo não se sentia diferente daquelas pessoas, pois, assim como a eles, lhe faltava liberdade e autonomia. Da mesma forma que tinham um senhor, ela também o tinha. Assim como esperavam por alguém que colocasse fim ao seu cativeiro, ela também o esperava.

Educada no deserto, negligenciada por seu pai, vivendo em meio aos escravos, ela não tinha outro socorro, outra consolação que sua compaixão e lágrimas, ela estava habituada a dizer: "Um dia virá em que tudo será mudado em minha vida, quando eu farei bem aos outros, um dia em que me amarão, e eu darei todo meu coração àquele que me der o seu; esperando, sofremos; calemo-nos, e guardemos nosso amor por recompensa a quem me libertará." Esse libertador, esse messias não veio. (SAND, 1832, p. 80, tradução minha) ${ }^{9}$

Indiana sobrevive a prisões que encarceraram seu corpo e sua mente com o acesso limitado à educação, um marido que acreditava que a "mulher foi feita para obedecer" (SAND, 1832, p. 291 $)^{10}$ e um amante que a enganara e abandonara. A liberdade e felicidade que tanto

\footnotetext{
${ }^{9}$ Élevée au désert, négligée de son père, vivant au milieu des esclaves, pour qui elle n'avait d'autre secours, d'autre consolation que sa compassion et ses larmes, elle s'était habituée à dire : «Un jour viendra où tout sera changé dans ma vie, où je ferai du bien aux autres, un jour où l'on m'aimera, où je donnerai tout mon coeur à celui qui me donnera le sien ; en attendant, souffrons ; taisons-nous, et gardons notre amour pour récompense à qui me délivrera. »Ce libérateur, ce messie n'était pas venu (SAND, 1832, p. 80).

${ }^{10}$ Les femmes sont faites pour obéir, replit M. Delmare (SAND, 1832, p. 291).
} 
lhe convinham só lhe foram possíveis ao perceber que poderia optar por uma vida distante dos jugos sociais no interior da Ilha de Bourbon e não sendo subserviente a uma figura masculina, mas a tendo por companhia.

O termo "escrava" é empregado pelo narrador e pela protagonista, sustentado em suas falas a partir do período que é possível elencar como evolução da personagem. Em posse do conhecimento da sua situação e da violência do domínio patriarcal, extrapola o silêncio e concebe a sua subjetividade como inegociável. Na seguinte citação, Indiana declara ao marido suas convicções e a consciência de sua condição social:

- Eu sei que sou sua escrava e você o meu senhor. A lei desse país faz de você meu dono. Você pode comandar meu corpo, prender minhas mãos, governar minhas ações. Você possui o direito do mais forte, e a sociedade confirma isso; mas sobre minha vontade, você não pode nada, somente Deus a pode curvar e reduzir. Procure uma lei, um calabouço, um instrumento de suplício que lhe dê poder sobre mim! [...] Você pode me impor o silêncio, mas não pode me impedir de pensar. (SAND, 1832, p.221, tradução minha) ${ }^{11}$

Beauvoir (1980) afirma que a mulher já nasce escrava e questiona as razões que a levam a se submeter às opressões, o que dialoga com o panopticismo ${ }^{12}$ que induz o prisioneiro à condição consciente da vigilância de que está refém, demonstrando que o poder está presente em todos os lugares e que é vedado o direito de se desfazer das identidades instituídas (FOUCAULT, 2005, p. 175). Nesse ponto, compreende-se a justificativa do silêncio e da subordinação ainda que conscientes quanto ao funcionamento do sistema misógino enunciado no romance.

\footnotetext{
${ }^{11}$ Je sais que je suis l'esclave et vous le seigneur. La loi de ce pays vous a fait mon maître. Vous pouvez lier mon corps, garotter mes mains, gouverner mes actions. Vous avez le droit du plus fort, et la société vous le confirme ; mais sur ma volonté, monsieur, vous ne pouvez rien, Dieu seul peut la courber et la réduire. Cherchez donc une loi, un cachot, un instrument de supplice qui vous donne prise sur moi ![...] Vous pouvez m'imposer silence, mais non m'empêcher de penser (SAND, 1832, p. 221).

${ }^{12}$ Em sua obra Vigiar e Punir (2005), Foucault discute acerca do sistema de vigilância e controle social a que os sujeitos são submetidos na contemporaneidade. Para tanto, utiliza o termo panóptico para designar essa sociedade disciplinar. Originalmente, o termo foi cunhado por Jeremy Betham, em 1785, e se refere a uma penitenciaria na qual um único vigilante observa todos os presidiários, enquanto os mesmos não sabem se estão ou não sendo observados. Por essa razão, esses manterão disciplina e comportamento adequados.
} 


\section{O corpo e a feminilidade}

A feminilidade está frequentemente atrelada a diversos gestos sociais e estereótipos que elucidem beleza, recato, obediência e fragilidade, de tal maneira que se solidifica na manutenção do papel social da mulher. Com foco voltado para a protagonista, a feminilidade, no romance, se encontra marcada desde a caracterização da personagem até a fragilidade corpórea e emocional de Indiana, passando por suas falas, reações amedrontadas diante da violência do marido, amabilidade e preocupação com os demais do seu convívio. Esse tipo de identidade é trivialmente ensejada nas obras do período romântico, no entanto essa formalidade é mantida até certo nível da narrativa. Visto que há um desenvolvimento no sentido emancipatório por parte da protagonista que age no sentido de desfazer o veio tradicional da feminilidade, por meio da desobediência e contestação discursiva, subvertendo os valores conferidos a ela.

No entorno de Indiana persiste uma aura de exotismo. Em momentos de fraqueza física, o narrador traceja a performatividade de gênero construída e regulada envolta na materialização de seu corpo que, inicialmente se mantém coerente com as imposições sociais. Em dissonância com o que o narrador alude sobre ser merecedora de todo o amor, os homens, o marido e o amante, exercem poder sobre seu corpo, a fim de submetê-la. Tal fato possibilita enxergá-los como alegorias do poder patriarcal e Indiana enquanto representante das mulheres em seus sofrimentos e na idealização da liberdade das mesmas.

Com o desenvolver do enredo e da personagem, a normalidade de consciência e imagem feminina são subvertidas. Os significados culturais inscritos sobre o corpo sexualizado de Indiana iniciam um processo de desconstrução. A personagem não deixa de ter as mesmas características físicas, contudo, no campo do pensamento, torna-se exemplo de abandono das normas sociais e do modelo de feminilidade hegemônico. O enunciador opta por desvencilharse desse tipo de representação conforme avança na formação da protagonista e na figura de Laure de Nangy. A descrição de Laure não carregada de detalhes sobre aspectos de sua aparência e, ao tratar de seus atos, pensamentos e personalidade, tangencia os aspectos performativos vinculados à feminilidade ao apresentar uma personagem forte, inteligente e emancipada. A personagem representa a possibilidade de uma vida mais livre e que só é possível por meio de suas posses. Revelando, assim, uma nova concepção de feminilidade que remete à força transformadora da mulher. 
Contudo, se há nesse jogo crítico uma personagem que encarna todos os jugos sociais que repousam sobre as mulheres, essa personagem é Noun, a criada "criola" de Indiana que se suicida em decorrência do engano e da rejeição que transpassa o campo amoroso como também o social. Noun representa a impossibilidade de uma vida livre, o sufocamento da alteridade, o trancafiamento da mulher subalterna, a ausência do saber, a subjugabilidade do colonizado. Sand, de uma forma sútil, subverte a consagrada cena de Shakespeare ao colocar no lugar do corpo morto de uma nobre flutuando sobre as águas uma jovem criada sem perspectivas de futuro diante do extrato social. Sua rejeição não foi puramente por amor como a de Ophélia, sua loucura tinha origem e classe social, visto que o desprezo por ela sofrido advinha dessas condições.

Tanto a violência simbólica, aquela exercida por meio das leis, moral e discursos reguladores, quanto a violência física se apresentam no romance de Sand. Se M. Delmare é marcado pelos traços de um homem violento, Indiana é sublinhada como aquela "que sabia muito bem resistir à violência de seu marido" (SAND, 1832). Fosse na forma grosseira com que se direcionava a ela, no silenciamento que lhe era imposto, na obediência cega que lhe fora prescrita, todas essas formas de violência simbólica estão em plano proeminente, na obra, de forma a mostrar os estágios desse processo de violência que culmina na agressão física e tentativa de feminicídio.

Talvez, se ela tivesse tardado alguns minutos, esse homem infeliz teria tido tempo de voltar a si mesmo; mas a má sorte dos dois quis que ela se apresentasse quase imediatamente diante dele. Então, sem poder articular uma frase, ele a agarrou pelos cabelos, a derrubou, e a feriu com a frente do salto de sua bota. [...] ele viu, sobre a varanda, Indiana que havia se levantado, e que limpava, com um ar calmo e frio, o sangue que inundava seu rosto. De início, como ele acreditava tê-la matado, experimentou um sentimento de alegria vendo-a de pé, e depois sua cólera se reacendeu. (SAND, 1832, p. 408409 , tradução minha) ${ }^{13}$

\footnotetext{
${ }^{13}$ Peut-être, si elle eût tardé quelques minutes, cet homme malheureux aurait eu le temps de rentrer en lui-même ; mais leur mauvaise étoile à tous deux voulut qu'elle se présentât presque aussitôt devant lui. Alors, sans pouvoir articuler une parole, il la saisit par les cheveux, la renversa, et la frappa au front du talon de sa botte. [...] il vit, sous la varangue, Indiana qui s'était relevée, et qui essuyait, d'un air calme et froid, le sang dont son visage était
} 
Foucault (2005) afirma que o discurso reforça o poder e, ao mesmo tempo, o subverte. A protagonista enseja retirar-se do panopticismo e subverte esse poder na forma discursiva, nos embates com seu marido, bem como em seu retorno a seu país junto de Sir Ralph, seu primo, com o qual viverá em meio à natureza e longe das legislações sociais.

Ao tocar na conjuntura escravocrata, a escritora vai além da simples apropriação do termo para apontar a exploração e o cárcere que também recaíam sobre as mulheres. Indiana e seu primo e companheiro Ralph, ao final da narrativa, se retiram na ilha de Bourbon a fim de viver uma vida tranquila e livre dos jugos sociais. Eles usam de suas posses para comprar e pôr em liberdade homens e mulheres em condição de escravos.

A maior parte de nossos rendimentos é consagrada a recomprar pobres negros enfermos. É a principal causa do mal que os colonos dizem de nós. Que nós somos muito ricos por libertar todos os que vivem na escravidão! Nossos servos são nossos amigos; eles partilham das nossas alegrias, nós curamos seus males. É assim que nossa vida se passa, sem tristezas, sem remorsos. (SAND, 1832, p. 538, tradução minha) ${ }^{14}$

Essa postura abolicionista transparece na passagem de Indiana de mulher-objeto para mulher-sujeito que rompe com o mundo, saindo do estado de resignação para o estado de deliberação e independência. Concebendo-se agora enquanto livre, ao passo que proporciona certa liberdade e cuidado àqueles que, como ela anteriormente, se encontram em regime de servidão, não devido ao gênero, mas à etnia.

O encontrar-se consigo mesma lhe possibilitou o desnudamento da alteridade. Ela é o exemplo do que Funck (2011, p. 67) declara sobre a mulher: "um indivíduo cuja subjetivação ocorre dentro de normas e comportamentos socialmente definidos como femininos pelo contexto cultural em que se insere, seja aceitando-os ou rebelando-se contra eles". No caso da

inondé. D'abord, comme il croyait l'avoir tuée, il éprouva un sentiment de joie en la voyant debout, et puis sa colère se ralluma (SAND, 1883, p. 408-409).

${ }^{14} \mathrm{La}$ majeure portion de nos revenus est consacrée à racheter de pauvres noirs infirmes. C'est la principale cause du mal que les colons disent de nous. Que ne sommes-nous assez riches pour délivrer tous ceux qui vivent dans l'esclavage ! Nos serviteurs sont nos amis ; ils partagent nos joies, nous soignons leurs maux. C'est ainsi que notre vie s'écoule, sans chagrins, sans remords. (SAND, 1832, p. 538) 
protagonista, a desconstrução dessas normas e a rebelião são apresentadas, de forma que a narrativa estabelece um processo oposicionista à dominação.

Ao unir as reflexões, é possível engendrar que o nome Indiana tem seu significado inserido no campo dos desejos e realizações que se encontram na autonomia do sujeito, no viver sem rótulos e demandas sociais, no primitivismo que se delineia pela ausência de normas e modulações do indivíduo. Indiana remete à alteridade, à emancipação, à descolonização da mente e do corpo, representa a transição do estado de tutela à existência autêntica e rebelde.

\section{CONSIDERAÇÕES FINAIS}

A expressão literária consente na realização da ambivalência do real e do ficcional. Indiana é um romance que se estabelece no campo literário como parte inaugural do arcabouço literário que dedicou sua enunciação às demandas sociais. Ademais, é uma das primeiras produções literárias de autoria feminina que traz em sua narrativa reivindicações feministas, através da exposição sobre a condição das mulheres.

A literatura do século XIX tem uma missão, Sand tinha uma missão. Um romance cujo tema principal é o matrimônio e a forma com que a mulher é subjugada dentro dessa instituição mantém, em sua constituição, diversos aspectos e artifícios linguísticos tencionando o projeto de falar de si, de um local de fala para o outro.

Contempla-se, dessa forma, um romance cujo enredo é desenvolvido dentro de um período histórico, um romance que perpassa o real e o imaginário, que excede o limite através da maneira com que retrata uma gama de perfis políticos distintos entre si, os quais representam várias figuras sociais e até aquela que seria em suma a idealização da mulher em ascensão à emancipação, a mulher-sujeito; além da maciça e relevante crítica social que se estende à política da época, até a mais clara situação da mulher na sociedade de 1830.

\section{REFERÊNCIAS BIBLIOGRÁFICAS}

BEAUVOIR, Simone de. O Segundo Sexo. Rio de Janeiro, Nova Fronteira, 1949.

BORDAS, Éric. Indiana de George Sand. Saint-Amand: Gallimard, 2004.

BOURDIEU, Pierre. Razões práticas: sobre a teoria da ação. Trad. Mariza Corrêa. Campinas: Papirus Editora, 1996. 
BUTLER, Judith. Variações sobre sexo e gênero: Beauvoir, Wittig e Foucault. In: Seyla Benhabib e Drucilla Cornell (coords.), Feminismo como crítica da modernidade. Rio de Janeiro: Rosa dos Tempos, 1987.

CANDIDO, Antônio. 2000. Literatura e Sociedade. Ouro sobre Azul: $9^{\mathrm{a}}$ ed. Rio de Janeiro, 2006.

FOUCAULT, Michel. O panoptismo. In: Vigiar e Punir: nascimento da prisão. 30. ed. Petrópolis: Vozes, 2005.

FUNCK, Susana. O que é uma mulher? In: GOMES, André; STEVENS, Cristina. Revista Cerrados Palavra e poder: representações na literatura de autoria feminina, n.31, ano 20. Universidade de Brasília, 2011.

HUNT, Lynn. Revolução Francesa e Vida Privada. In: Perrot, Michelle. (org.). História da vida na privada, 4: Da Revolução Francesa à Primeira Guerra. São Paulo: Companhia das Letras, 1991.

MAINGUENEAU, Dominique. O discurso literário. Trad. Adail Sobral. São Paulo: Contexto, 2006.

PERROT, Michelle. Revolução francesa e vida privada. In: P, Michelle. (org.). História da vida privada, outrora em outro lugar. Trad. Denise Bottmann e Bernardo Joffily. São Paulo: Companhia das Letras, 1991.

As mulheres ou os silêncios da história. Trad. Viviane Ribeiro. Bauru: EDUSC, 2005.

RENARD, Marie-Reine. Les idées religieuses de George Sand et l'émancipation féminine. Archives de sciences sociales des religions, 2004, p. 25-38.

SAID, Edward. Imperialismo e cultura. Trad. Denise Bottman. São Paulo: Companhia das Letras, 1995.

SAND, George. Indiana. Paris: La mode, 1832.

. Histoire de ma vie. Paris: Calmann-Lévy, 1855.

Correspondance entre George Sand et Gustave Flaubert: Préface de Henri Amic.

Paris: Calmann-Lévy, 1904.

ZOLIN, Lúcia Osana. Crítica feminista. In: BONNICI, Thomas; Zolin, L. O. (org.). Teoria literária: abordagens históricas e tendências contemporâneas. 3. ed. ver. ampl. Maringá: EDUEM, 2009. 